\title{
Effect of coagulation pretreatment on membrane distillation process for desalination of recirculating cooling water
}

\author{
Jun Wang ${ }^{\mathrm{a}}$, Dan $\mathrm{Qu}^{\mathrm{a}}$, Muer Tie ${ }^{\mathrm{b}}$, Haijing Ren ${ }^{\mathrm{a}}$, Xianjia Peng ${ }^{\mathrm{a}}$, Zhaokun Luan ${ }^{\mathrm{a}, *}$ \\ a State Key Laboratory of Environmental Aquatic Chemistry, Research Center for Eco-Environmental Sciences, Chinese Academy of Sciences, \\ P.O. Box 2871, Beijing 100085, PR China \\ ${ }^{\mathrm{b}}$ North United Power Corporation, Huhhot 010021, PR China
}

\section{A R T I C L E I N F O}

\section{Article history:}

Received 16 January 2008

Received in revised form 27 July 2008

Accepted 28 July 2008

\section{Keywords:}

Membrane distillation

Coagulation

Desalination

Recirculating cooling water

\begin{abstract}
A B S T R A C T
The objective of this work was to study the performance of coagulation pretreatment and the effect of coagulation pretreatment on membrane distillation (MD) process for desalination of recirculating cooling water (RCW). In this study, RCW was desalinated by MD process after pretreated by coagulation, precision filtration, acidification and degassing. Pre-coagulation of RCW with poly-aluminum chloride (PACl) coagulant improves the elimination of total organic carbon (TOC), total phosphorus (TP) substances. The optimized $\mathrm{pH}$ value and $\mathrm{PACl}$ dosage were 7 and $15 \mathrm{mg} / \mathrm{L}$, respectively. Compared with MD process without coagulation pretreatment, much slighter MD flux decrease was observed when coagulation pretreatment was employed for desalination of RCW using MD process. Compared with the membrane flux of MD process for the RCW without coagulation pretreatment, about 23\% improvement of MD flux was obtained by employing coagulation pretreatment after 30 days operation. The variation of crystal morphology on membrane surface and hydrophobic character of PVDF hollow membranes were investigated. The results show that distorted rhombic magnesium-calcite scale formed on membrane surface when coagulation pretreatment was employed. However, the deposited magnesium-calcite on the membrane surface was loosely packed with particles of much smaller size when RCW without coagulation pretreatment was fed. It is because that the coagulation pretreatment removed most of the natural organic matter (NOM) and antiscalant additives in RCW, which act as an inhibitor to calcium carbonate crystal growth in water. After coagulation pretreatment, bigger crystal deposit formed on membrane surface with the increase in CF of RCW. It was rather difficult for bigger crystal to enter membrane pores and thus the formation of bigger crystal reduced partial wetting of membrane, which enhanced trans-membrane flux. The hydrophobic character of PVDF hollow membranes used in MD process can be easily recovered by chemical rinsing using acid-base solutions. The results indicate that the pretreatment with chemical coagulant, $\mathrm{PACl}$, is effective for the desalination of RCW by MD process.
\end{abstract}

Crown Copyright @ 2008 Published by Elsevier B.V. All rights reserved.

\section{Introduction}

In many regions of the world, especially in droughty regions, the reuse of RCW as boiler makeup water has been of growing interest and has turned into an obligatory requirement with the growth of fresh water demand. Conventional method for the desalination of RCW is a combination of conventional techniques such as chemical addition, coagulation/flocculation, sedimentation, sand filtration, biochemical treatment and disinfection prior to desalination by ion exchange [1]. But the ion-exchange technology has a number of disadvantages such as significant space requirements,

\footnotetext{
* Corresponding author. Tel.: +86 10 62849198; fax: +86 1062849198

E-mail address: lijinmeihouhou@163.com (Z. Luan).
}

long treatment time, high running cost, and ion-exchange resins must be regenerated by additive chemical reagents (acid and alkali) when they are saturated and this causes serious secondary pollution.

Until recently, the two major types of technologies that are used for the desalination of RCW can be broadly classified as thermal process and membrane process. Thermal desalination technology can be sub-divided into three groups: Multi-Stage Flash Distillation (MSF), Multi-Effect Distillation (MED), and Vapor Compression Distillation (VCD) [2,3]. These processes have rarely been used for desalination of RCW, because of the high costs involved. Membrane technologies can be subdivided into three broad categories: Electrodialyis/Electrodialysis Reversal (ED/EDR), Reverse Osmosis (RO) [3]. In power plant, RO technology has gained significant popularity and its application for treatment of RCW is increasing. But the RO membranes can be particularly susceptible to scaling and foul- 
ing and regular membrane cleaning is necessary. The key issue for successful RO plant operation is proper feed water pre-treatment, since RCW is mostly near saturation for several constituents and contain relatively high concentration of suspended solids. The pretreatment for RO typically consists of lime softening and filtration. However, membrane fouling has resulted frequently from poor softener/clarifier performance. At present, pretreatment such as coagulation, sedimentation, sand filtration, microfiltration (MF) and ultrafiltration (UF) are increasingly being used for the removal of suspended solids and biological matter from RCW before RO systems. These pretreatment processes combined with RO process are integrated membrane systems (IMS) [4-6], which have become of great interest in recent years. However, the IMS have several drawbacks that have been difficult to overcome, such as the water recovery rates are usually lower than $70 \%$, for a price often considered as uneconomic due to capital and energy costs, and have complicated pre-treatment and post-treatment, high operation and maintenance requirements. Furthermore, unlike thermal processes, $\mathrm{RO}$ membranes do not provide high purity water [7].

The direct contact membrane distillation (DCMD) process is a kind of thermally driven membrane separation process, in which two solutions at different temperatures are separated by a microporous hydrophobic membrane. The driving force of DCMD is vapour pressure difference across the membrane resulting from the temperature gradient in the boundary layers adjacent to the membrane surface. DCMD has been applied for water desalination, heavy metal recovery, waste water reuse and food concentration processing, and so on. The theory and application of DCMD have been described in many papers [8-11]. Further more, DCMD process not only was applied for the desalination of RCW, but also was coupled with RCW system for pure water production. A novel cleaner production technology using waste heat for pure water production was established by integration of DCMD and traditional RCW system [10].

In comparison with other separation operations, MD has obvious advantages: almost a complete rejection of dissolved and non-volatile species, lower operating pressure than pressuredriven membrane processes, reduced vapour space compared to traditional distillation, low operating temperature of a feed enables the utilization of waste heat as a preferable energy source [12-18]. Although the MD technology has the advantages that other membrane technologies have not, one of main obstacles impeding the implementation of MD is membrane fouling, which is caused by interactions between the membrane and the various components during the process [16].

Coagulation process had been applied abroad as one effective pretreatment technology in membrane separation processes. The coagulation process alters the stability of colloidal particles, which plays a significant role in fouling. This may increase the water flux and decrease the effect of fouling, thus reducing operational cost. Much study shows that MD process has lower pretreatment requirement than other membrane separation processes in the field of surface water/groundwater desalination, such as UF, RO and NF $[8,17]$. But, as for RCW, Desalination by MD process is complex and challenging, because RCW generally consists of high total dissolved solids (TDS), and large amounts of scale inhibitor, corrosion inhibitor and biocide, which contain cupreous chelate complex and phosphorous compound, were added to the RCW system to achieve the aim of high concentration factor operation. The influence of coagulation pretreatment on MD process is less studied in MD process.

The objective of this work was to study the performance of coagulation pretreatment in RCW desalination process and the influence of coagulation pretreatment on MD process.
Table 1

The quality parameter of RCW

\begin{tabular}{|c|c|}
\hline Constituent & Data \\
\hline Sodium (mg/L) & 196.9 \\
\hline Potassium (mg/L) & 49.2 \\
\hline Chloride (mg/L) & 232.1 \\
\hline Sulfate $(\mathrm{mg} / \mathrm{L})$ & 306.1 \\
\hline Silica (mg/L, as $\left.\mathrm{SiO}_{2}\right)$ & 12.9 \\
\hline Carbonate $(\mathrm{mmol} / \mathrm{L})$ & 0.54 \\
\hline Bicarbonate (mmol/L) & 6.8 \\
\hline Calcium (mg/L) & 156.3 \\
\hline Magnesium (mg/L) & 55.1 \\
\hline Total hardness $(\mathrm{mmol} / \mathrm{L})$ & 6.20 \\
\hline $\mathrm{pH}$ & 8.8 \\
\hline Conductance $(\mu \mathrm{S} / \mathrm{cm})$ & 1894 \\
\hline $\mathrm{TP}(\mathrm{mg} / \mathrm{L})$ & 0.6602 \\
\hline SS (NTU) & 5.42 \\
\hline TOC (mg/L) & 16.35 \\
\hline Total dissolved solids (mg/L) & 1193 \\
\hline
\end{tabular}

\section{Materials and methods}

\subsection{Feed water}

The No. 4 RCW of Dalate Coal-Fired power plant in Inner Mongolia of China was used for the study. The concentration factor (CF) of this RCW was usually controlled in the range of 2-3. The samples were preserved in dark containers, stored at $4{ }^{\circ} \mathrm{C}$ and adding $1 \mathrm{mg} / \mathrm{L}$ sodium acid to prevent any alteration to the chemical character of organic matter by ultraviolet radiation or micro-organism growth. These water quality parameters are shown in Table 1.

For comparison, saturated $\mathrm{CaCO}_{3}$ solution was used as feed water to investigate the variation of membrane flux in MD process. Saturated $\mathrm{CaCO}_{3}$ solution was prepared according to Hillner et al. [18]. A solution of $100 \mathrm{mM} \mathrm{NaHCO} 3$ was added slowly to $1000 \mathrm{~mL}$ of $40 \mathrm{mM} \mathrm{CaCl}_{2}$ with continuous stirring until the solution became turbid. The final $\mathrm{pH}$ was adjusted to 8.2 with $10 \mathrm{M} \mathrm{NaOH}$. The solution was filtered sterile through a filter with pores of $0.22 \mu \mathrm{m}$ and stored in glass bottles at $4{ }^{\circ} \mathrm{C}$.

\subsection{Membrane distillation experiment}

Based on the DCMD Principle, an experimental device was set up. A schematic diagram of the experimental device for the RCW concentration is shown in Fig. 1. The MD device is made up of membrane module, two glass heat exchangers and accessorial materials such as cycle pumps, valves, water reserviores and measure meters. The RCW was pretreated by coagulation, precision filtration, acidification and degassing pretreatment processes before feeding into hot brine tank for MD desalination. For the sake of clarity, each unit will be described separately.

\subsubsection{Pretreatment}

Coagulation, precision filtration, acidification and degasification units were utilized as pretreatment process for the MD process. Coagulation process was used to eliminate NOM and suspended substance (SS) in RCW.

After the coagulation and sedimentation processes, the RCW was pumped into a precision filter with filtration precision of $5 \mu \mathrm{m}$, and then the $\mathrm{pH}$ was adjusted using $0.2 \mathrm{~mol} / \mathrm{L} \mathrm{HCl}$. Because acidification treatment resulted in the increase in $\mathrm{CO}_{2}$ concentration in $\mathrm{RCW}$, the degassing treatment followed the acidification can reduce the $\mathrm{CO}_{2}$ concentration and prevent the $\mathrm{CO}_{2}$ permeating into the cold side, which can resulted in the decrease in $\mathrm{pH}$ and the increase in electrical conductivity of pure water. 


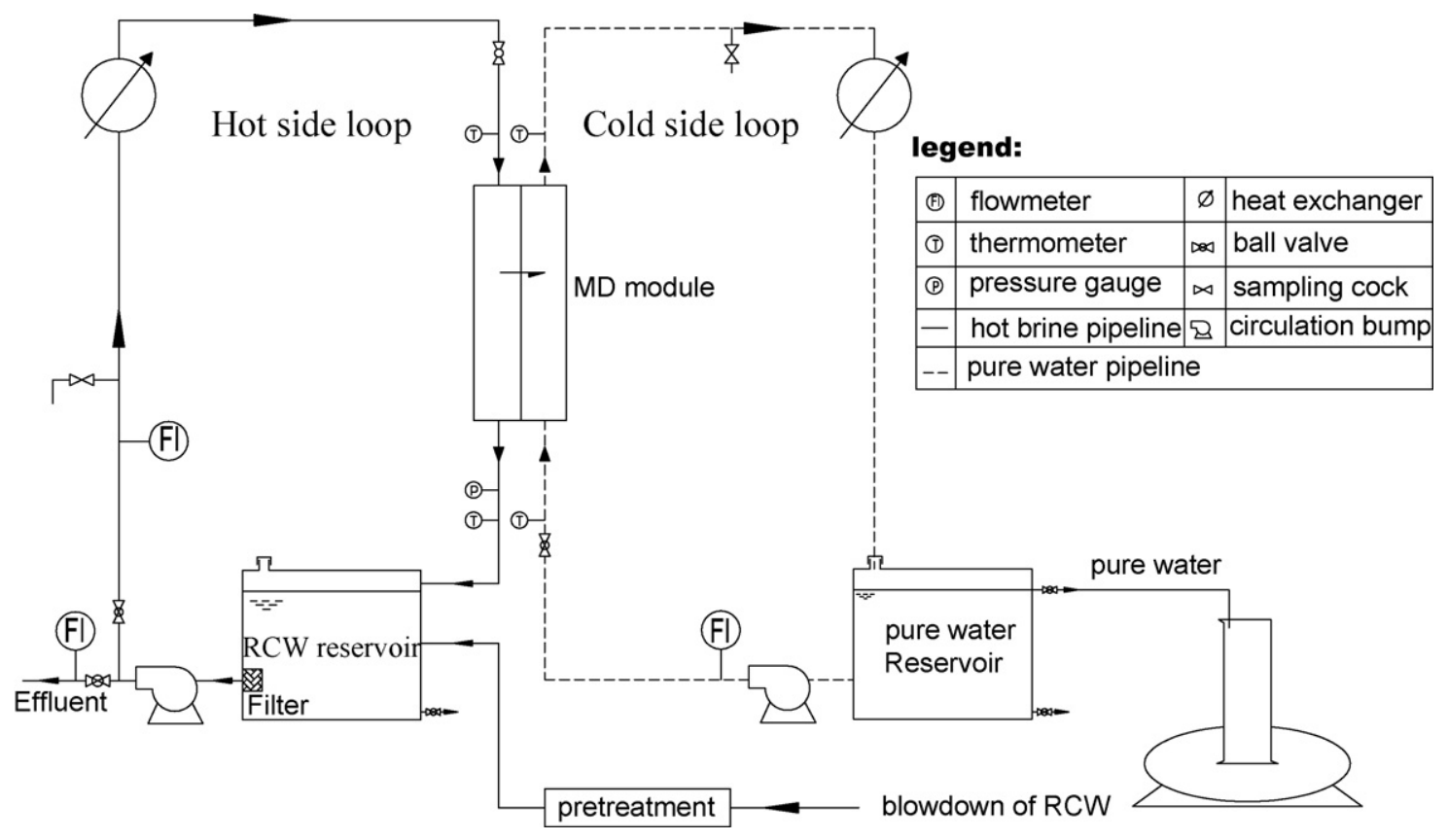

Fig. 1. A schematic diagram of the MD experimental setup.

Vacuum membrane degasification was utilized to achieve near complete removal of dissolved gases like $\mathrm{CO}_{2}, \mathrm{O}_{2}$, etc. from RCW. A small and compact porous hydrophobic polypropylene hollow fibers membrane module (model XL02B, supplied by Beijing Xianlu Membrane Company), has yielded excellent degasification.

\subsubsection{Membrane and membrane module}

The microporous polyvinylidene fluoride (PVDF) hollow fiber membrane was prepared by the authors by a dry/wet phase inversion processes. The diameters of the membranes, nominal pore diameter and porosity were $d_{\text {out }} / d_{\text {in }}=1.3 / 1.0 \mathrm{~mm}, 0.18 \mu \mathrm{m}$ and $82 \%$, respectively. The minimum pressure which water will overcome the hydrophobic forces of the membrane and will penetrate with the pores $(\mathrm{LEP}$ ) is $150 \mathrm{kPa}$.

The shell was set up by gluing a polyester tube (diameter ( $\mathrm{mm}$ ), $D_{\mathrm{i}} / D_{\mathrm{o}}=15 / 20$ ) to two UPVC T-tubes. The module has a total length of $240 \mathrm{~mm}$ and an effective length of $100 \mathrm{~mm}$. The total area of the membrane was about $0.0157 \mathrm{~m}^{2}$.

\subsubsection{Membrane distillation unit}

In Fig. 1, RCW and pure water were contained in two glass reservoirs with a capacity of $3000 \mathrm{~mL}$ and $200 \mathrm{~mL}$, respectively, and were driven by two magnetic pumps (mode MP-15RN, purchased from Shanghai Seisun Bumps Co., Ltd.). The feed flows inside the hollow fibers, whereas the distillate flows through the inter-tubular space. The temperature of fluid in the hot side loop was controlled by pumping through a glass heat exchanger which located in a constant temperature water tank.

The feed flow rate through the lumen of membrane module (hot side) and the pure water flow rate through the shell side of membrane module (cold side) were monitored using two rotameters (model LZT-1001M-V, purchased from Yuyao Yinhuan Flowmeter Co., Ltd.) equipped with a back pressure value for the manual regulation of the flow rate. As to preserve the MD process integrity, the flow rates and pressures were selected by taking into account that the pressure difference should not exceed $65 \%$ of the $\mathrm{LEP}_{\mathrm{W}}$ of the fibres. Two pressure meters (model YJTF100, purchased from Nanjing Wanda Co., Ltd.) connected to the lumen and shell side of the module was used to measure the pressure difference at both sides in the range $0-100 \mathrm{kPa}$. The temperature of both fluids was monitored at the inlet and outlet of the membrane module using four Pt-100 thermoresistances connected to a digital thermometer (Digit RTD, model XMT-808, purchased from Yuyao Changjiang Temperature Meter Instrument Factory) to provide an accuracy of $\pm 0.2^{\circ} \mathrm{C}$.

\subsection{Experimental procedure and methods}

\subsubsection{Coagulation/pretreatment}

The collected RCW was used as feed water for MD experiment after coagulation, precision filtration, acidification and degassing processes pretreatment. Coagulation was performed by the jar test. PACl was selected as coagulant. Coagulant dosage and the $\mathrm{pH}$ of RCW were varied to study their effect on TOC, TP and SS removal. PACl was added in raw RCW and agitated for $23 \mathrm{~min}$ (rapid mixing of $3 \mathrm{~min}$ at $100 \mathrm{rpm}$, slow mixing of $20 \mathrm{~min}$ at $30 \mathrm{rpm}$. These conditions had been experimentally determined to be optimum). The dosages of coagulant were 10,15, 20, 25 and $30 \mathrm{mg} / \mathrm{L}$, respectively. The $\mathrm{pH}$ of RCW was adjusted to $5,6,7$, and 8 by $0.2 \mathrm{~mol} / \mathrm{L} \mathrm{HCl}$. The coagulated water was then settled for $30 \mathrm{~min}$. The TOC, TP and turbidity in the supernatant were measured.

\subsubsection{Membrane distillation}

In the study of the effect of coagulation pretreatment on desalination process for RCW by MD, five same membrane modules were used for MD experiments. The pure water production was collected in a continuous way. To adjust or control the CF of RCW, the MD device was carefully controlled by continuous purging a portion of the concentrated RCW (Blowdown) from the system and replacing with fresh RCW (Make-up). The CF of RCW was constant $(\mathrm{CF}=5.0)$ over the entire course of MD investigations.

Three runs were employed to study the effect of coagulation pretreatment of RCW on MD. The feed waters for three runs were: saturated calcium carbonate solution, RCW without coagulation pretreatment and RCW with coagulation pretreatment, 
respectively. The feed water were fed into hot side reservoir after precision filtration, acidification ( $\mathrm{pH}$ 5.0) and degassing pretreatment except for the saturated calcium carbonate solution, and the $\mathrm{pH}$ of feed water of run 2 and run 3 were adjusted to 5.0 by $0.2 \mathrm{~mol} / \mathrm{L}$ $\mathrm{HCl}$.

The membrane modules were installed vertically in the MD installation. The control system maintained fixed values of flow and temperature of streams at the inlet of module. The inlet temperature of feed and distillate were constant for all the experiments at $323 \mathrm{~K}$ and $293 \mathrm{~K}$. The flow rates of both sides were maintained at $0.5 \mathrm{~m} / \mathrm{s}$ and $0.2 \mathrm{~m} / \mathrm{s}$, respectively. During all experiments the feed was supplied inside the hollow fiber membrane, whereas the distillate flowed through the inter-capillary space of MD module.

\subsubsection{Analytical methods}

The collected samples were analyzed for parameters such as $\mathrm{pH}$, alkalinity, conductivity, total hardness, calcium, TDS, SS, chloride, sodium, potassium and sulphate, and so on. The chloride ions concentration was measured using a Digital Titrator (Model 16900, Hach Company) with silver nitrate method. The concentration of sulphate was determined by the turbidimetric method (precipitation by $\mathrm{BaCl}_{2}$ ). Total phosphate concentration was determined using a Hach model DR/4000U spectrophotometer, by phosphorus reactive method. Dissolved calcium concentration was determined by EDTA titration, using murexide as indicator. The electrical conductivity and the total dissolved solids of treated wastewaters and MD permeates were measured with a portable meter (sensION ${ }^{\mathrm{TM}}$ 156, HACH Company), at a temperature of $20^{\circ} \mathrm{C}$. Turbidity was determined using a HACH 2100 turbidimeter. TOC in the solutions was measured with a TOC analyzer (Tekmar-DOHRMANN Pheonix 8000). The morphology and composition of the deposit layer formed on the membrane surface were studied using scanning electron microscopy (SEM, S-3000N, Hitachi company) coupled with energy dispersion spectrometry (EDS, EDAX company, USA). Contact angles (CAs) were measured on a CA meter (Contact Angle System OCA20, Dataphysics Co., Germany) under ambient temperature. Water droplets of about $0.5 \mu \mathrm{L}$ were carefully dropped onto the as-prepared coating through a syringe and the CAs were obtained by measuring five different positions of each sample.

The MD flux transported through the membrane was determined by the measurement of an increase of pure water volume on the cold side. The values of the MD flux were calculated from the equation:

$J=\frac{V_{2}-V_{1}}{A t}\left(\mathrm{~L} \mathrm{~m}^{-2} \mathrm{~h}^{-1}\right)$

where $V_{1}$ is the volume of water out the cold side pure water tank of the MD system at the start of the MD process, $\mathrm{L}$. $V_{2}$ is the volume of water out the cold side pure water tank at the end of the MD process, L. $A$ is the membrane area of hollow fiber membranes in the MD module, $\mathrm{m}^{2}$, and $t$ is the time of the pure water collection in the MD process, $h$.

In this study, chloride concentration variation was used as the criterion of CF [1], $K$ is measured from ratio of the concentration of Chloride between the blowdown and the makeup RCW.

$K=\frac{\left[\mathrm{Cl}^{-}\right]_{\mathrm{b}}}{\left[\mathrm{Cl}^{-}\right]_{\mathrm{m}}}$

where $K,\left[\mathrm{Cl}^{-}\right]_{\mathrm{b}}$ and $\left[\mathrm{Cl}^{-}\right]_{\mathrm{m}}$ are $\mathrm{CF}$ of $\mathrm{RCW}$, chloride concentration of the blowdown and chloride concentration of the fluid in makeup, respectively.

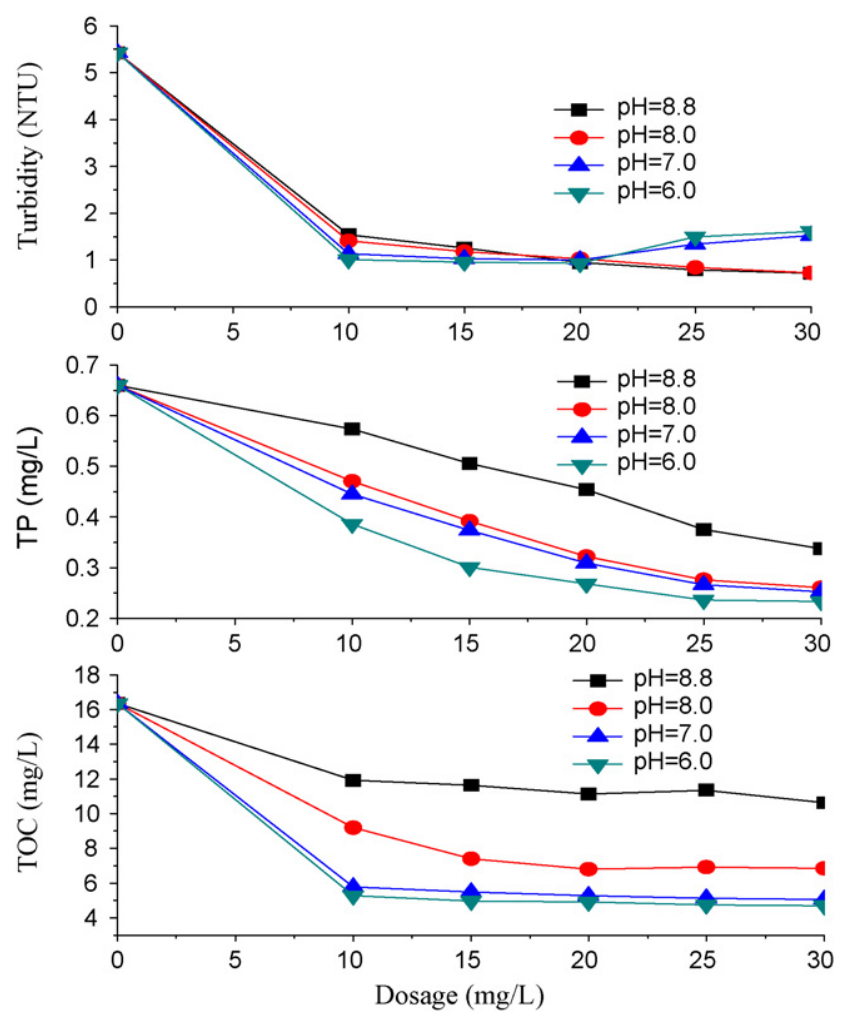

Fig. 2. Effect of coagulant dosage and $\mathrm{pH}$ on removal of TOC/TP/turbidity.

\section{Results and discussion}

\subsection{The coagulation pretreatment of RCW}

The removal of TOC, TP and turbidity as a function of PACl dosage at different $\mathrm{pH}$ is shown in Fig. 2. The initial pH of RCW is 8.8. As the dosage of $\mathrm{PACl}$ increased from 10 to $30 \mathrm{mg} / \mathrm{L}$, the removal percentages for TOC and TP increased at all $\mathrm{pH}$ values investigated and the removal of TOC and TP increased with the decrease in $\mathrm{pH}$ at the same dosage. The removal percentage of TOC varies from $28.8 \%$ to $69.7 \%$ in the $\mathrm{pH}$ range of $6.0-8.8$ at the dosage of $15 \mathrm{mg} / \mathrm{L}$. The removal percentage of TOC reaches $66.4 \%$ at a PACl dosage of $10 \mathrm{mg} / \mathrm{L}$ at $\mathrm{pH} 7.0$. The removal of TOC increased slowly as the dosage of $\mathrm{PACl}$ increased from 10 to $30 \mathrm{mg} / \mathrm{L}$ at solution of 6.0 and 7.0.

The effect of coagulation treatment on turbidity levels is also shown in Fig. 2. It can be seen that $\mathrm{PACl}$ dosage and solution $\mathrm{pH}$ had less effect on the removal of turbidity. At $\mathrm{pH} 8.0$ and 8.8, when $\mathrm{PACl}$ dosage increased from 10 to $30 \mathrm{mg} / \mathrm{L}$, the turbidity removal increased slightly. Maximum turbidity removal has been achieved using $30 \mathrm{mg} / \mathrm{L} \mathrm{PACl}$ at $\mathrm{pH} 8.8$. However, at $\mathrm{pH} 6.0$ and 7.0 , it appeared that with increasing coagulation dosage, turbidity removal increased first and then decreased and when PACl dosage was higher than $20 \mathrm{mg} / \mathrm{L}$, the removal percentages of turbidity decreased.

Considering both removal efficiency and $\mathrm{PACl}$ cost, $\mathrm{PACl}$ dosage and solution $\mathrm{pH}$ were optimized to be $15 \mathrm{mg} / \mathrm{L}$ and 7.0 , respectively.

NOM in RCW can be partially removed by coagulation process in terms of two distinct mechanisms: charge neutralization and sweep flocculation [19]. The TP in RCW was removed mainly by adsorption of the polymeric hydrolysate at the same conditions [20]. The experimental results show that the removal of TOC, TP was effected by solution $\mathrm{pH}$. This can be explained as follows. At neutral $\mathrm{pH}$ and weak acidic/alkaline $\mathrm{pH}$ values, the Coagulant PACl 


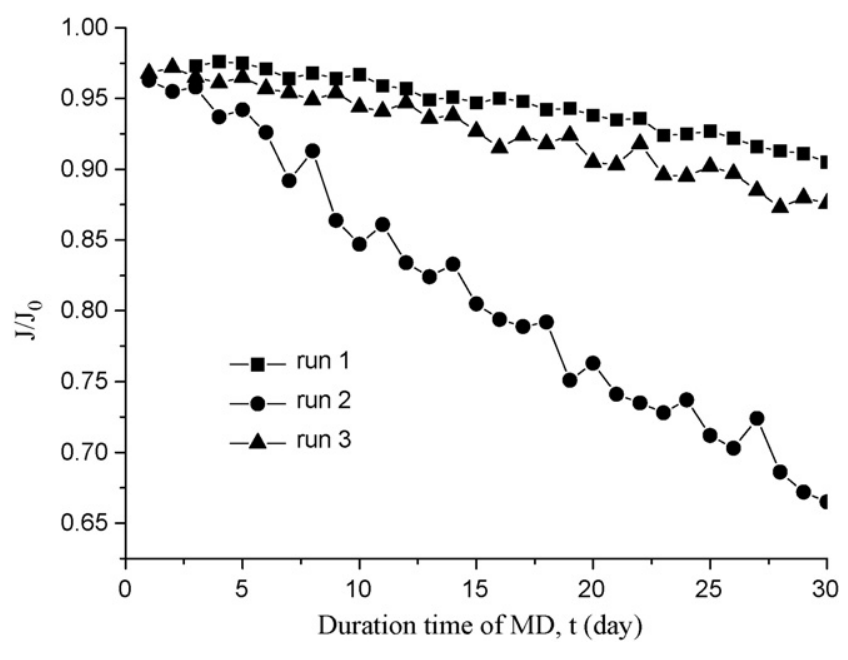

Fig. 3. Normalized flux $\left(J / J_{0}\right)$ vs. time for desalination of three runs. The feed water for run 1 was saturated calcium carbonate solution. RCW for run 2 was the one with precision filtration, acidification $(\mathrm{pH} \mathrm{5.0)}$ and degassing pretreatment. RCW for run 3 was the one with coagulation, precision filtration, acidification ( $\mathrm{pH}$ 5.0) and degassing pretreatment.

was hydrolyzed to yield cationic polymeric hydrolysate. However, NOM such as humic acids at neutral $\mathrm{pH}$ are negatively charged due to the ionization of $\mathrm{COOH}$ and phenolic $\mathrm{OH}$ groups [21], so the NOM molecules are slightly dissociated and their surface charge is weak. At lower pH values, these functional groups are mostly protonated, which makes humic acid less negatively charged, this decreases their hydrodynamic radii, and reduces electrical repulsion among functional groups, resulting in decrease in apparent size, increases hydrophobicity and their tendency to be adsorbed by PAC polycations.

\subsection{Effect of coagulation pretreatment of RCW on $M D$}

Fig. 3 shows the effect of the pretreatment of RCW on the MD flux of the MD process. Normalized flux $\left(J / J_{0}\right)$ calculated by dividing the flux along the operation time by the initial flux $\left(J_{0}\right)$ was plotted against operation time. The feed water for run 1 was saturated calcium carbonate solution. RCW for run 2 was the one with precision filtration, acidification ( $\mathrm{pH}$ 5.0) and degassing pretreatment. RCW for run 3 was the one with coagulation, precision filtration, acidification ( $\mathrm{pH}$ 5.0) and degassing pretreatment. For the pretreatment, the coagulation process for RCW was operated with $15 \mathrm{mg} / \mathrm{L}$ of PACl. The electrical conductivity of pure water of the three runs in the cold side during experimental periods always varied in the range of $2.5-5.0 \mu \mathrm{S} / \mathrm{cm}$.

It can be seen that, for run 1, run 2 and run 3, the flux decrease with the running time. However, the flux decrease for the run with no coagulation pretreatment is much more rapid. At the end of 30 days running, the Normalized flux of run 1 and run 3 decreased from $0.968,0.966$ to 0.905 and 0.876 , respectively. However, the Normalized flux of run 2 decreased obviously from 0.964 to 0.664 .
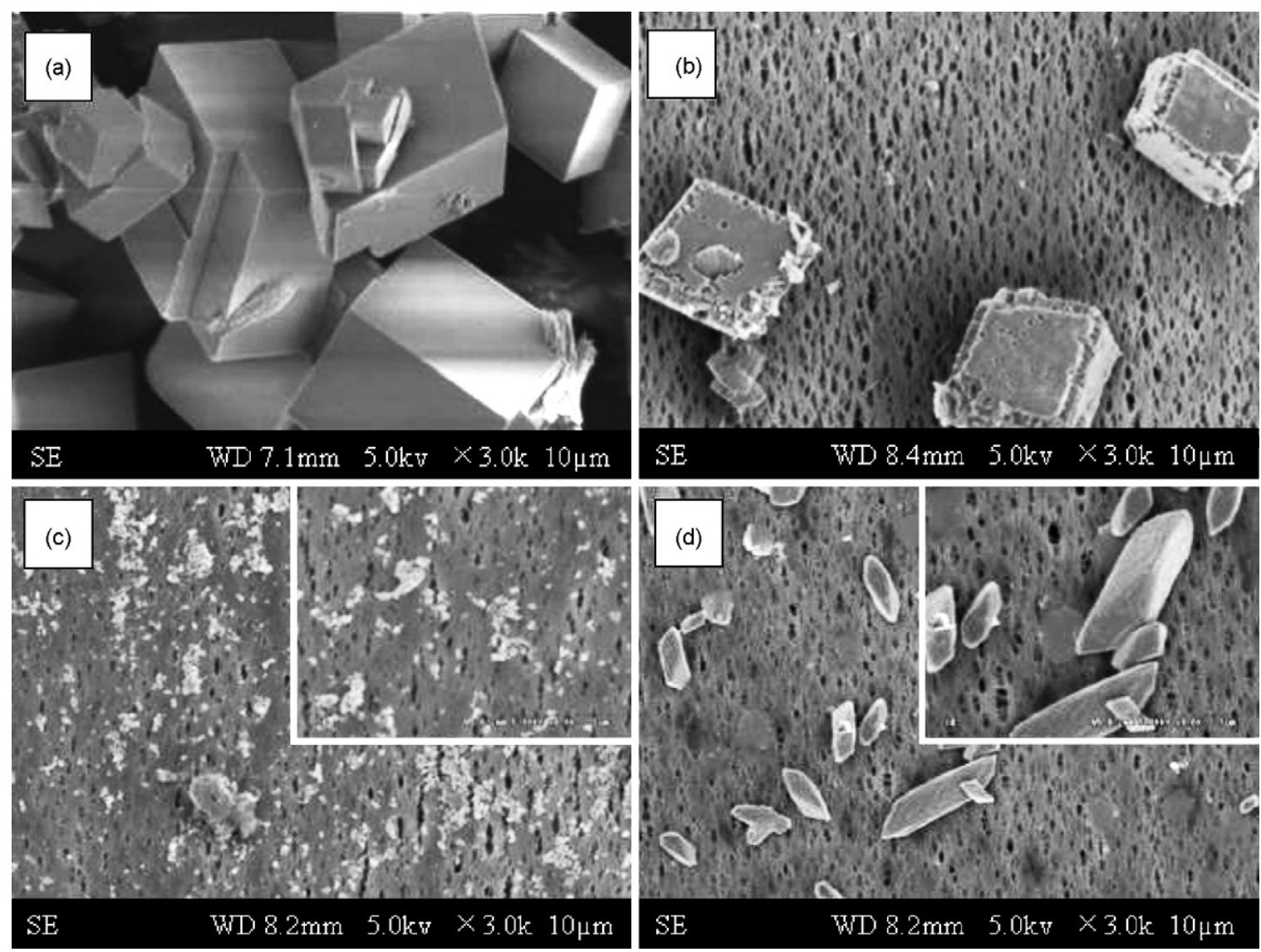

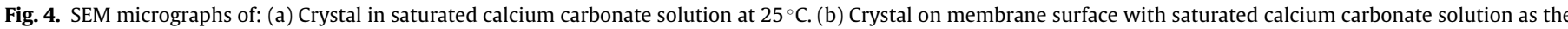

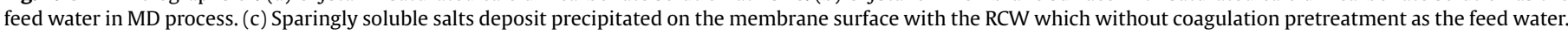

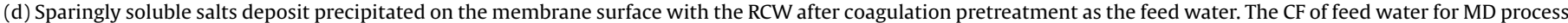
was about 5.0. Inseted are shown general views of selected areas (SEM magnification: $8000 \times$ ). 
For run 1 with saturated calcium carbonate solution as the feed water, calcium carbonate will form when the $C F$ increased and the temperature increased. To prevent calcium carbonate deposit precipitated on the membrane surface, the saturated calcium carbonate solution was fed into hot side of membrane modules after filtration with the fixed filter in the hot side reservoir. MD flux results on the calcium carbonate system show that no significant loss in water vapour permeation is observed. SEM micrograph also shows the calcium carbonate crystal on membrane surface (Fig. 4b). By comparison of Fig. 4b with Fig. 4c and d, it can be seen that calcium carbonate crystal on membrane surface is much fewer in Fig. 4b. Possible explanations for this resistance to scaling are the nature of the compact layer on the surface and that for salts with inverse solubility characteristics (that is to say, the solubility of which decreases with increase the temperature of solution), maximum supersaturation can occur in the bulk of the flow rather than at the membrane surface [8].

The rapid MD flux decrease in run 2 maybe is due to the effect of NOM in RCW. For RCW, the concentration of NOM of RCW usually reaches 2-5 times NOM concentration of the makeup water for cooling water. The main components of NOM are humic substances, which are macromolecular mixtures of humic acids, fulvic acids, and humin [22]. The NOM, especially the macromolecular humic substances can form coagulate form with $\mathrm{Ca}^{2+}$. Humic acid contain negatively charged carboxyl groups. $\mathrm{Ca}^{2+}$ acts like a binding agent of two carboxyl functional groups. The deposition can be increased by charge screening. The coagulate form are also more favourably adsorbed onto hydrophobic membranes due to the sorption between humic macromolecules and hydrophobic membranes.

For run 3, the TOC of feed water varied from 16.2 to $5.3 \mathrm{mg} / \mathrm{L}$ by coagulation pretreatment, the coagulation pretreatment can effectively reduce the macromolecular humic substances [21]. In MD process, the influence of NOM on scale decreased and the MD flux decrease is much slighter.

\subsection{Crystal morphology on membrane surface}

The DCMD is a kind of thermally driven membrane separation process in which two solutions at different temperatures are separated by a microporous hydrophobic membrane. The driving force of DCMD is the formation of a vapour pressure difference across the membrane resulting from the temperature gradient in the boundary layers adjacent to the membrane surface. DCMD can be employed to concentrate aqueous solution. In the MD concentration process, the precipitation of $\mathrm{CaCO}_{3}$ and other sparingly soluble salts takes place due to the decomposition of bicarbonate ions (calco-carbonic system) and the concentration of sparingly soluble salts ions. The $\mathrm{CaCO}_{3}$ scaling was found to be the major problem during desalinated water production by MD. It is well known that operation conditions, NOM, many ions such as $\mathrm{Mg}^{2+}, \mathrm{Ba}^{2+}, \mathrm{Sr}^{2+}$, $\mathrm{Mn}^{2+}$ and $\mathrm{SO}_{4}{ }^{2-}$ affect $\mathrm{CaCO}_{3}$ growth rate. Especially, NOM interacts strongly with calcium carbonate and acts as an inhibitor to calcium carbonate crystal growth in aquatic systems [23-27]. Hence, as a result of heating the feed and enhancement of $\mathrm{CF}$, the solubility of $\mathrm{CaCO}_{3}$ goes down with temperature rise, and the $\mathrm{HCO}_{3}{ }^{-}$ions present in the RCW undergo the decomposition and a considerable amount of $\mathrm{CaCO}_{3}$ precipitates on membrane surface, which reduces the surface of water vapourization (pores). The increase of MD flux by coagulation pretreatment for RCW desalination can be explained by the variation of crystal morphology on membrane surface.

Fig. 4 was the SEM micrographs of crystal on membrane surface at different run mode. Fig. 4a was SEM micrograph of crystal in saturated calcium carbonate solution at $25^{\circ} \mathrm{C}$. The perfect calcite crystal was rhombohedral. Without NOM in saturated calcium carbonate solution, all calcite crystals are perfect, the surface of the calcite crystals was smooth. However, when saturated calcium carbonate solution was used as feed water, calcite crystals with edge and the surface of the rhombohedron distorted was observed (Fig. 4b). This indicates that the MD conditions (temperature, flow rate, etc.) have significant effect on crystallization. Fig. 4c shows the morphology of calcite formed on membrane surface with NOM in the RCW. The deposit of calcite crystals on the membrane surface was loosely packed and dispersive, and the color of inner membrane surface became brown. It is suggested that NOM acts as an inhibitor to calcium carbonate precipitation by blocking the active growth sites through adsorption reaction [24]. Otherwise, in the RCW, additional protection from scaling may be attained through the use of a number of proprietary antiscalant additives, such as polymaleic acid, phosphonates and non-ionic detergents. Those antiscalant additives suppressed the growth of calcite crystals. Thus, all of those will result in a complex fouling layer on membrane surface.

Fig. $4 \mathrm{~d}$ shows the calcite scale on membrane surface with the RCW after coagulation pretreatment as the feed water. The distorted rhombic calcite crystals are the main contribution to the crystals.

When comparing Fig. 4c with Fig. 4d, we found that the size of crystal particle in Fig. 4c was much smaller than that in Fig. 4d. The size of crystal particles in Fig. 4c was in the range of $0.2-1.5 \mu \mathrm{m}$ while the size of crystal particles in Fig. $4 d$ was in the range of 2.5-7.5 $\mu \mathrm{m}$. It is obvious that smaller dimension of the crystals located on the membrane surface (Fig. 4c) facilitates the deposition of crystallites inside the membrane pores, which will result in a partial wetting of membrane surface step by step. Partial wetting of membrane can accelerate the surface wetting of membrane, scale formation on membrane surface and reduction of the effective membrane area for mass transport [16]. Hence, a marked membrane flux decline was observed in the MD process for run 2.

In the MD process for desalination of RCW, formation of membrane fouling is inevitable and the membrane flux will decrease gradually. So, periodic cleaning of membrane will be necessary. In this study, for the cleaning of membranes, hollow membranes were rinsed using $2 \%(\mathrm{w} / \mathrm{w}) \mathrm{HCl}$ solution and $2 \%(\mathrm{w} / \mathrm{w}) \mathrm{NaOH}$ solution for $30 \mathrm{~min}$ each. The change of hydrophobic character of the membranes used in MD process was investigated. The SEM pictures of inner surface of the fresh PVDF membrane, membrane for run 2, membrane for run 3, and membrane after rinsing were presented in Fig. 5. The profiles of a water droplet on the inner surface of PVDF membranes were presented in the insert of Fig. 5. The CA with water in Fig. 5a, b, c, and d was $94.5 \pm 2.3^{\circ}, 73.6 \pm 2.6^{\circ}, 72.3 \pm 3.1^{\circ}$ and $88.8 \pm 2.2^{\circ}$, respectively. Obviously, the membrane for MD process of RCW with coagulation pretreatment has a CA very close to the membrane for desalination of RCW without coagulation pretreatment. The CA of inner membrane surface significantly increases from $72.3 \pm 3.1^{\circ}$ to $88.8 \pm 2.2^{\circ}$ after the membranes being rinsed. A comparison with Fig. $5 \mathrm{c}$ and $\mathrm{d}$ reveals that the majority of the deposit covering the membrane surface was removed. Only a slight amount of crystallites, as shown in Fig. 5d, remained on the membrane surface. This confirms that the hydrophobic character of membranes can be easily recovered by chemical rinsing using acid-base solutions.

The composition of crystallites were analysed by the SEM-EDS method (Fig. 6). Beside of the major component (Ca), small amounts of $\mathrm{Mg}$ were also determined. In the RCW for this study, the $\left[\mathrm{Mg}^{2+}\right] /\left[\mathrm{Ca}^{2+}\right]$ was about 0.35 . When $\mathrm{Mg}^{2+}$ is present 


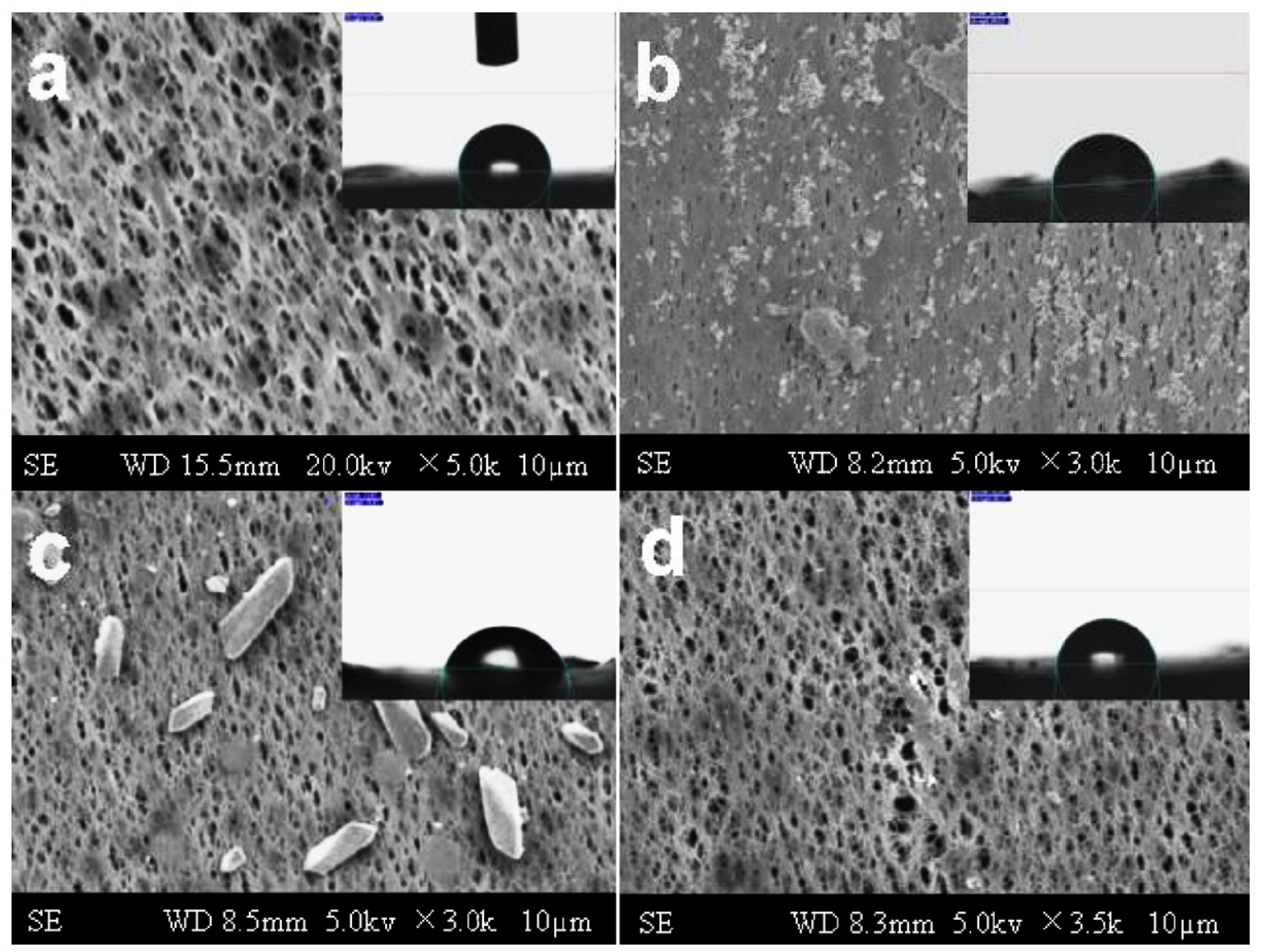

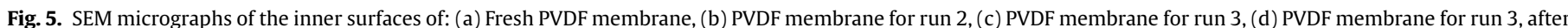
rinsing by $2 \%(\mathrm{w} / \mathrm{w}) \mathrm{HCl}$ solution and $2 \%(\mathrm{w} / \mathrm{w}) \mathrm{NaOH}$ solution. Inseted are the profiles of a water droplet on the inner surface of membranes.

in the scale formation solution, magnesium-calcite scale is formed. Magnesium-calcite interactions are strong because they are enhanced by electrostatic interactions. $\mathrm{Mg}^{2+}$ adsorbed on the surface of calcite caused the increase in surface roughness and dis- tortion of crystals. $\mathrm{Mg}^{2+}$ also suppressed vaterite formation and resulted in calcite dominated scale. The amount of $\mathrm{Mg}^{2+}$ being adsorbed may be influenced by the local solution chemistry and the precipitation rate [23].

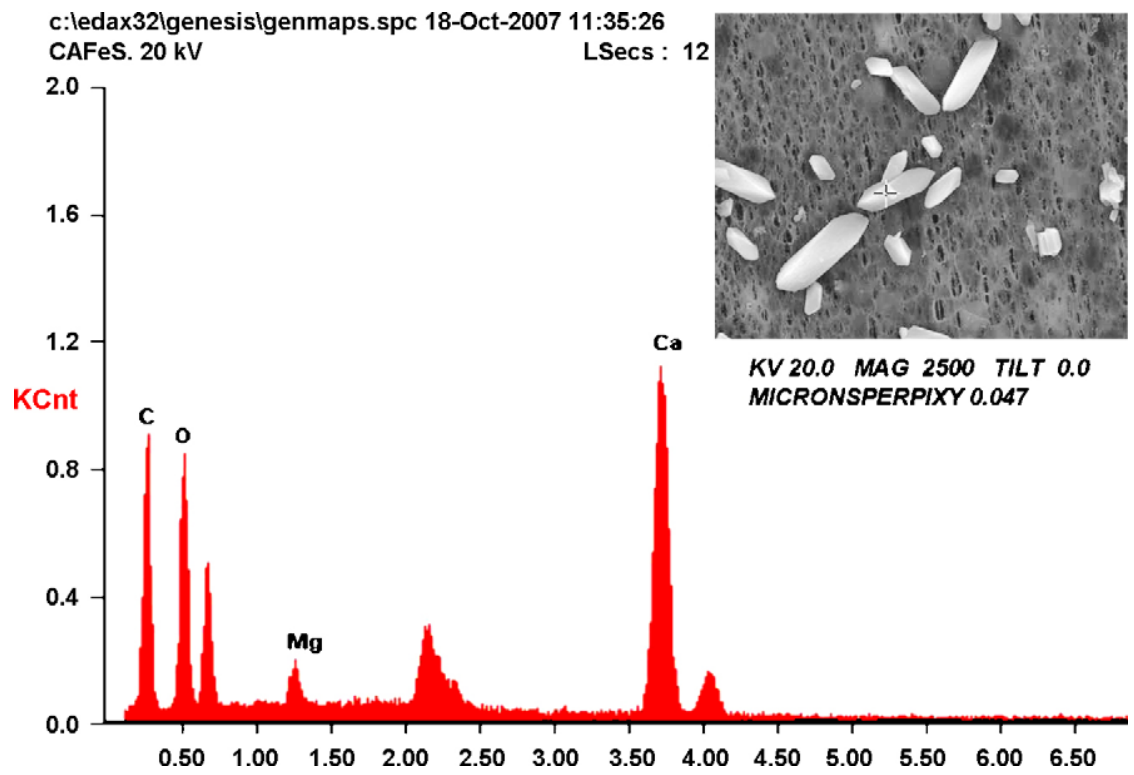

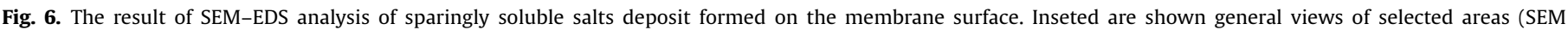
magnification: $3000 \times$ ). 


\section{Conclusions}

A detailed experimental study was conducted to investigate the influence of coagulation pretreatment with $\mathrm{PACl}$ coagulant on the performance of MD process for RCW desalination. The results led to the following conclusions:

1. Pre-coagulation of RCW with PACl coagulant improves the elimination of TOC, TP substances. The removal of TOC and TP increase with the decrease in $\mathrm{pH}$. The dosage of $\mathrm{PACl}$ and $\mathrm{pH}$ had less effect on the removal of turbidity. The optimal PACl dosage and $\mathrm{pH}$ value were $15 \mathrm{mg} / \mathrm{L}$ and 7.0 , respectively.

2. In the MD process for the desalination of RCW, the membrane flux decreased gradually. The much rapid MD flux decrease was observed when RCW was not pretreated. About $23 \%$ of improvement of flux was obtained by using the pretreated RCW in the end of experiment period. This result indicates that the pretreatment with chemical coagulant, $\mathrm{PACl}$, is effective for the desalination of RCW.

3. The investigation of the variation of crystal morphology on membrane surface shows that the distorted rhombic magnesium-calcite scale formed on membrane surface with RCW after coagulation pretreatment as feed water. Whereas, the deposit of calcite crystals on the membrane surface was loosely packed and dispersive when RCW was not pretreated. It is because the NOM, antiscalant additives and $\mathrm{Mg}^{2+}$ in RCW act as an inhibitor to calcium carbonate crystal growth in aqueous phase. After coagulation pretreatment, the bigger crystals deposit on membrane surface lower the chance of membrane partial wetting and results in a higher membrane flux. The hydrophobic character of PVDF hollow membranes can be easily recovered by chemical rinsing using acid-base solutions.

The effect of coagulation pretreatment on MD process for RCW desalination process is suggested to be due to the fact that the coagulation pretreatment can remove substantial parts of NOM and results in a much larger scaling particle size, which will reduce the partial wetting of membrane.

\section{Acknowledgements}

Financial support provided by the National Natural Science Foundation of China (under Grant No. 50678169) and the National Science and Technology Support Program of China (under Grant No. 2006BAJ08B05) is gratefully acknowledged.

\section{References}

[1] P. Lens, P.L. Hulshoff, P. Wilderer, T. Asano, Water Recycling and Resource Recovery in Industry: Analysis, Technologies and Implementation, IWA Publishing, UK, 2002.
[2] E. El-Zanati, K.M. El-Khatib, Integrated membrane-based desalination system, Desalination 205 (2007) 15-25.

[3] C. Fritzmann, J. Löwenberg, T. Wintgens, T. Melin, State-of-the-art of reverse osmosis desalination, Desalination 216 (2007) 1-76.

[4] Z. Wang, Z.F. Fan, L.X. Xie, S.C. Wang, Study of integrated membrane systems for the treatment of wastewater from cooling towers, Desalination 191 (2006) $117-124$.

[5] J. Zhang, L. Chen, H. Zeng, X. Yan, X. Song, Pilot testing of outside-in MF and UF modules used for cooling tower blowdown pretreatment of power plants, Desalination 214 (2007) 287-298.

[6] K. Karakulski, M. Gryta, Water demineralisation by NF/MD integrated processes, Desalination 177 (2005) 109-119.

[7] J.H. Hanemaaijer, J. van Medevoort, A.E. Jansen, C. Dotremont, E. van Sonsbeek, T. Yuan, L.D. Ryck, Memstill membrane distillation-a future desalination technology, Desalination 199 (2006) 175-176.

[8] M.S. El-Bourawi, Z.W. Ding, R.Y. Ma, M. Khayet, A framework for better understanding membrane distillation separation process, J. Membr. Sci. 285 (2006) 4-29.

[9] J. Gilron, L. Song, K.K. Sirkar, Design for cascade of crossflow direct contact membrane distillation, Ind. Eng. Chem. Res. 46 (2007) 2324-2334.

[10] J. Wang, B. Fan, Z.K. Luan, D. Qu, X.J. Peng, D.Y. Hou, Integration of direct contact membrane distillation and recirculating cooling water system for pure water production, J. Clean. Prod. 16 (2008) 1847-1855.

[11] L. Song, B. Li, K.K. Sirkar, J. Gilron, Direct contact membrane distillation-based desalination: novel membranes, devices, larger-scale studies, and a model, Ind. Eng. Chem. Res. 46 (2007) 2307-2323.

[12] Z. Ding, L. Liu, Z. Li, R. Ma, Z. Yang, Experimental study of ammonia removal from water by membrane distillation (MD): the comparison of three configurations, J. Membr. Sci. 286 (2006) 93-103.

[13] L. Martinez, J.M. Rodriguez-Maroto, Effects of membrane and module design improvements on flux in direct contact membrane distillation, Desalination 205 (2007) 97-103.

[14] M. Gryta, M. Tomaszewska, K. Karakulski, Wastewater treatment by membrane distillation, Desalination 198 (2006) 67-73.

[15] M. Gryta, Long-term performance of membrane distillation distillation process, J. Membr. Sci. 265 (2005) 153-159.

[16] M. Gryta, Influence of polypropylene membrane surface porosity on the performance of membrane distillation process, J. Membr. Sci. 287 (2007) 67-78.

[17] F. Macedonio, E. Curcio, E. Drioli, Integrated membrane systems for seawater desalination: energetic and exergetic analysis, economic evaluation, experimental study, Desalination 203 (2007) 260-276.

[18] P.E. Hillner, A.J. Gratz, S. Manne, P.K. Hansma, Atomic scale imaging of calcite growth and dissolution in real time, Geology 20 (1992) 359-362.

[20] S.H. Lee, C.H. Lee, Effect of membrane properties and pretreatment on flux and NOM rejection in surface water nanofiltration, Sep. Purif. Technol. 56 (2007) $1-8$.

[21] B.Z. Dong, Y. Chen, N.Y. Gao, J.C. Fan, Effect of pH on UF membrane fouling, Desalination 195 (2006) 201-208.

[22] M. Khayet, A. Velázquez, J.I. Mengual, Direct contact membrane distillation of humic acid solutions, J. Membr. Sci. 240 (2004) 123-128.

[23] T. Chen, A. Neville, M.D. Yuan, Influence of $\mathrm{Mg}^{2+}$ on $\mathrm{CaCO}_{3}$ formationbulk precipitation and surface deposition, Chem. Eng. Sci. 61 (2006) 5318-5327.

[24] Y.P. Lin, P.C. Singer, G.R. Aiken, Inhibition of calcite precipitation by natural organic material: kinetics, mechanism, and thermodynamics, Environ. Sci. Technol. 39 (2005) 6420-6428.

[25] P. Zuddas, K. Pachana, D. Faivre, The influence of dissolved humic acids on the kinetics of calcite precipitation from seawater solutions, Chem. Geol. 201 (2003) 91-101.

[26] I. Lebron, D.L. Suarez, Calcite nucleation and precipitation kinetics as affected by dissolved organic matter at $25^{\circ} \mathrm{C}$ and $\mathrm{pH}>7.5$, Geochim. Cosmochim. Acta 60 (1996) 2765-2776.

[27] A.R. Hoch, M.M. Reddy, G.R. Aiken, Calcite crystal growth inhibition by humic substances with emphasis on hydrophobic acids from the Florida Everglades, Geochim. Cosmochim. Acta 64 (2000) 61-72. 